\title{
High resolution aerosol data from MODIS satellite for urban air quality studies
}

Research Article

\author{
A. Chudnovsky ${ }^{1,2 *}$, A. Lyapustin ${ }^{3 \dagger}$, Y. Wang ${ }^{4 \neq}$, C. Tang ${ }^{1 \S}$, J. Schwartz $^{19}$, P. Koutrakis ${ }^{1 * *}$ \\ 1 Department of Environmental Health, Harvard School of Public Health, Boston, MA, USA \\ 2 Department of Geography and Human Environment, Tel-Aviv University, Israel, Tel: +972-3-6407049 \\ 3 GEST / UMBC, NASA Goddard Space Flight Center, Baltimore, MD, USA \\ 4 University of Maryland, Baltimore County, Baltimore, MD, USA
}

Received 1 July 2013 ; accepted 23 September 2013

\begin{abstract}
The Moderate Resolution Imaging Spectroradiometer (MODIS) provides daily global coverage, but the $10 \mathrm{~km}$ resolution of its aerosol optical depth (AOD) product is not suitable for studying spatial variability of aerosols in urban areas. Recently, a new Multi-Angle Implementation of Atmospheric Correction (MAIAC) algorithm was developed for MODIS which provides AOD at $1 \mathrm{~km}$ resolution. Using MAIAC data, the relationship between MAIAC AOD and $\mathrm{PM}_{2.5}$ as measured by the 27 EPA ground monitoring stations was investigated. These results were also compared to conventional MODIS $10 \mathrm{~km}$ AOD retrievals (MOD04) for the same days and locations. The coefficients of determination for MOD04 and for MAIAC are $R^{2}=0.45$ and 0.50 respectively, suggested that $A O D$ is a reasonably good proxy for $\mathrm{PM}_{2.5}$ ground concentrations. Finally, we studied the relationship between $\mathrm{PM}_{2.5}$ and $A O D$ at the intra-urban scale $(\leqslant 10 \mathrm{~km})$ in Boston. The fine resolution results indicated spatial variability in particle concentration at a sub- 10 kilometer scale. A local analysis for the Boston area showed that the AOD-PM 2.5 relationship does not depend on relative humidity and air temperatures below $\sim 7^{\circ} \mathrm{C}$. The correlation improves for temperatures above $7-16{ }^{\circ} \mathrm{C}$. We found no dependence on the boundary layer height except when the former was in the range 250-500 m. Finally, we apply a mixed effects model approach to MAIAC aerosol optical depth (AOD) retrievals from MODIS to predict $\mathrm{PM}_{2.5}$ concentrations within the greater Boston area. With this approach we can control for the inherent day-to-day variability in the AOD-PM 2.5 relationship, which depends on time-varying parameters such as particle optical properties, vertical and diurnal concentration profiles and ground surface reflectance. Our results show that the model-predicted $\mathrm{PM}_{2.5}$ mass concentrations are highly correlated with the actual observations (out-of-sample $\mathrm{R}^{2}$ of 0.86 ). Therefore, adjustment for the daily variability in the AOD-PM 2.5 relationship provides a means for obtaining spatially-resolved $\mathrm{PM}_{2.5}$ concentrations.
\end{abstract}

Keywords: Remote Sensing $\cdot \mathrm{PM}_{2.5}$ exposure assessment • urban air quality • Aerosol Optical Depth • MODIS • MAIAC • mixed effects model.

(c) Versita sp. z o.o.

*E-mail: achudnov@hsph.harvard.edu, achudnov@post.tau.ac.il

${ }^{\dagger}$ E-mail: alexei.i.lyapustin@nasa.gov

‡E-mail: yujie.wang-1@nasa.gov
$\S E$-mail: cht710@mail.harvard.edu
'E-mail: joel@hsph.harvard.edu

**E-mail: petros@hsph.harvard.edu 


\section{Introduction}

The adverse health effects from particulate matter (PM) pollution with aerodynamic diameter $\leqslant 2.5 \mu \mathrm{m}\left(\mathrm{PM}_{2.5}\right)$ must be considered in developing policies to improve air quality [1]. Substantial epidemiologic literature has demonstrated that exposure to ambient particulate matter (PM) is associated with increased morbidity and mortality, particularly associated with cardiopulmonary disease $[2,3]$ and lung cancer $[3,4]$. Since PM is created by various anthropogenic and natural sources with vastly different atmospheric residence times, it has a high spatiotemporal variability. An accurate assessment of this variability is important as it leads not only to stronger associations between exposure and health but also to deeper understanding of epidemiological time-series studies [5, 6].

Routine measurements of ground-level $\mathrm{PM}_{2.5}$ concentrations by air quality monitoring networks are of great importance in assessing exposures, but their spatial coverage has been limited. However, recently it has become clear that satellite remote sensing can be an important tool to complement the ground level measurements. The relevant satellite-derived parameter is the aerosol optical depth (AOD) which quantifies the extinction of solar radiation at a given wavelength due to presence of aerosols in an atmospheric column. Because the satellite-derived AOD is a measure of how much light is absorbed/scattered by particles in the column that are affected by ambient conditions (e.g., variable humidity and consequently variable amounts of water adsorbed on particles), while $\mathrm{PM}_{2.5}$ mass is a measure of dry particles near the surface, these two parameters are not expected to be strictly correlated. Furthermore, to be used for air quality applications, including health studies, the satellite retrieved AOD data (e.g. a total column optical measurement) must be converted to estimates of $\mathrm{PM}_{2.5}$ concentrations (e.g. a surface-level particulate mass measurement). This type of analysis requires $\mathrm{PM}_{2.5}$-AOD collocated pairs which itself is a restrictive requirement [7].

Until recently, the main source of global satellite aerosol data was the MODIS satellite MOD04 algorithm, which provides data at a $10 \mathrm{~km}$ resolution. Recently, a new Multi-Angle Implementation of Atmospheric Correction (MAIAC) algorithm was developed for MODIS which provides aerosol information at $1 \mathrm{~km}$ resolution [8, 9]. We started with a direct comparison between MOD04 and MAIAC retrievals. Toward this end, we conducted a multiyear analysis to study the relation of same-day/same location AOD vs $\mathrm{PM}_{2.5}(2002-2008)$ in the southern part of New England. In addition, we conducted a multi-year analysis by breaking down AOD vs $\mathrm{PM}_{2.5}$ regressions by season (spring, summer, fall, winter) and by site location.
Furthermore, we studied the intra-urban (at scales less than $10 \mathrm{~km}$ ) variability of the relationship between $\mathrm{PM}_{2.5}$ and AOD for Boston. Finally, we explored whether it was possible to obtain accurate estimates of $\mathrm{PM}_{2.5}$ concentrations using a MAIAC AOD retrieval and mixed effects model approach (daily adjustment for $A O D$ vs $\mathrm{PM}_{2.5}$ relationship). Our goal was to show how variability in the AOD vs $\mathrm{PM}_{2.5}$ relationship can be captured by a statistical model during one year of data (January 1 through December 31, 2003).

\subsection{Ground level $\mathrm{PM}_{2.5}$ observations}

Twenty-four hour-integrated $\mathrm{PM}_{2.5}$ concentrations were measured at 26 U.S. Environmental Protection Agency (EPA) $\mathrm{PM}_{2.5}$ monitoring sites during 2002 - 2008 (Figure 1, highlighted by dots and Table 1). These include 15 sites from Massachusetts (MA) and 11 sites from Connecticut (CT). Sampling frequency differed by site and included samples collected every day, every third day, and every sixth day. Additionally, we used 24 hour-integrated $\mathrm{PM}_{2.5}$ concentrations from the Harvard School of Public Health (HSPH) supersite located near downtown Boston. Data from this site have been used in a large number of epidemiological studies to assess the temporal variability of individual and population exposures in the region.

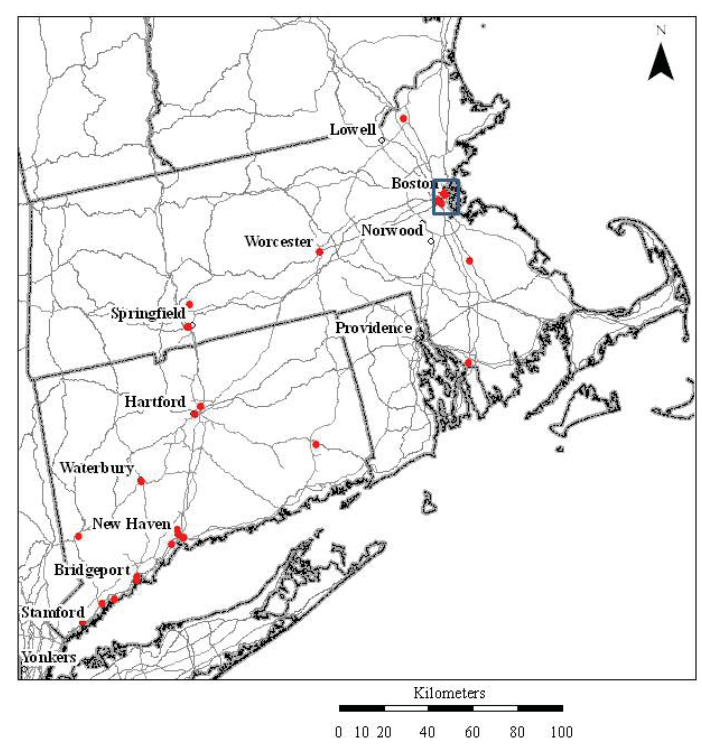

Figure 1. Study area and EPA monitoring sites for New England used for comparison between MOD04 and MAIAC data. Area highlighted by box is the Boston urban domain. 
Table 1. EPA ground monitoring sites used in this study over New England. Boston sites are highlighted in italic font.

\begin{tabular}{|c|c|c|c|}
\hline Site ID & City & Latitude & Longitude \\
\hline 09-001-0010 & Bridgeport, CT & 41.17 & -73.19 \\
\hline 09-001-0113 & Bridgeport, CT & 41.18 & -73.19 \\
\hline 09-001-1123 & Danbury, CT & 41.40 & -73.44 \\
\hline 09-001-2124 & Stamford, CT & 41.06 & -73.53 \\
\hline 09-001-3005 & Norwalk, CT & 41.11 & -73.41 \\
\hline 09-001-9003 & Westport, CT & 41.12 & -73.34 \\
\hline 09-003-1003 & E. Hartford, CT & 41.78 & -72.63 \\
\hline 09-003-1018 & Hartford, CT & 41.76 & -72.67 \\
\hline 09-009-0018 & New Haven, CT & 41.29 & -72.90 \\
\hline 09-009-0026 & New Haven, CT & 41.29 & -72.89 \\
\hline 09-009-1123 & New Haven, CT & 41.31 & -72.92 \\
\hline 09-009-2008 & New Haven, CT & 41.33 & -72.92 \\
\hline 09-009-2123 & Waterbury, CT & 41.55 & -73.04 \\
\hline 09-009-8003 & W. Haven, CT & 41.28 & -72.96 \\
\hline 09-011-3002 & Norwich, CT & 41.52 & -72.08 \\
\hline 25-005-1004 & Fall River, MA & 41.68 & -71.17 \\
\hline 25-009-2006 & Lynn, MA & 42.47 & -70.97 \\
\hline $25-009-5005$ & Haverhill, MA & 42.77 & -71.10 \\
\hline 25-013-0008 & Chicopee, MA & 42.19 & -72.56 \\
\hline 25-013-0016 & Springfield, MA & 42.11 & -72.59 \\
\hline 25-013-2009 & Springfield, MA & 42.11 & -72.60 \\
\hline 25-023-0004 & Brockton, MA & 42.08 & -71.01 \\
\hline 25-025-0027 & Boston, MA & 42.37 & -71.06 \\
\hline 25-025-0042 & Boston, MA & 42.33 & -71.08 \\
\hline $25-025-0043$ & Boston, MA & 42.36 & -71.05 \\
\hline 25-025-0002 & Boston, MA & 42.35 & -71.10 \\
\hline 25-027-0020 & Worcester, MA & 42.27 & -71.80 \\
\hline Harvard supersite & Boston, MA & 42.34 & -71.10 \\
\hline
\end{tabular}

\subsection{Satellite data}

A new algorithm MAIAC [8] has been developed to process MODIS data. MAIAC retrieves aerosol parameters over land at $1 \mathrm{~km}$ resolution simultaneously with parameters of a surface bidirectional reflectance distribution function (BRDF). This is accomplished by using the time series of MODIS measurements and simultaneous processing of a group of pixels. The MAIAC algorithm ensures that the number of measurements exceeds the number of unknowns, a necessary condition for solving an inverse problem that does not require the assumptions typically used by current operational algorithms. The MODIS time series accumulation also provides multi-angle coverage for every surface grid cell, which is required for the BRDF retrievals from MODIS data. The aerosol parameters include optical depth (total aerosol) and fine mode fraction. Following the MODIS operational aerosol algorithm
(MOD04) [9], models for the fine and coarse aerosol fractions are specified regionally based on the climatology of the Aerosol RObotic NETwork (AERONET) [10] sunphotometer data. AERONET validation over the continental USA showed that the MAIAC and MOD04 algorithms have a similar accuracy over dark and vegetated surfaces, but also showed that MAIAC generally improves accuracy over brighter surfaces, including most urban areas [8]. The improved accuracy of MAIAC resulted from the explicit surface characterization method, in contrast to the empirical surface parameterization approach, utilized in the MOD04 algorithm. Furthermore, MAIAC incorporates a cloud mask (CM) algorithm based on spatiotemporal analysis which augments traditional pixel-level cloud detection techniques [11]. In addition, the residual contamination by clouds and cloud shadows was reduced by discarding 2 pixels adjacent to detected clouds.

In addition to MAIAC data we used daily MODIS Level 2 (MOD04) Collection 5.1 Aerosol data from the Terra platform that are produced at a spatial resolution of $10 \times 10 \mathrm{~km}^{2}$ (at nadir). More details about the MODIS AOD retrieval are reported in $[8,12]$. We conducted a comparative analysis of AOD between MAIAC and the respective MOD04 product. It is important to mention that the MOD04 product is reported for an area of 20 by 20 , $500 \mathrm{~m}$ pixels in the swath format. This area corresponds to spatial resolution of $10 \times 10 \mathrm{~km}^{2}$ at nadir, however it grows with the scan angle reaching $\sim 20 \times 40 \mathrm{~km}^{2}$ at the edge of scan due to the respective growth of the MODIS pixel footprint by a factor of $\sim 2 \times 4$. Conversely, MAIAC provides a uniform $1 \mathrm{~km}$ gridded resolution at selected projection regardless of the scan angle. This means that the MAIAC product is under-sampled by a factor of 4 at nadir, considering maximal available spatial information from $500 \mathrm{~m}$ pixels, and is oversampled by a factor of 2 at the edge of scan. In this regard, MOD04 data are always under-sampled by a factor of 400 . In order to perform a direct MOD04-MAIAC comparison, the area of each MOD04 pixel was approximated by a polygon, and all MAIAC $1 \mathrm{~km}$ data fitting this area were averaged.

\subsection{Meteorological data}

All meteorological variables used in the analysis (temperature, boundary layer and relative humidity) were obtained through the National Climatic Data Center (NCDC) (NCDC, 2010). Only continuous operating stations with daily data running from 2000 to 2008 were used. In addition, we used meteorological data from Boston Logan airport. Grid cells were matched to the closest weather station for meteorological variables. 


\subsection{Data analyses}

We investigated the associations between AOD and $\mathrm{PM}_{2.5}$ daily measurements at the sampling sites for the years 2002-2008. We first made a direct comparison between MOD04 and MAIAC retrievals, with a multi-year analysis of AOD vs $\mathrm{PM}_{2.5}$ for the same days (2002-2008) and locations (27 EPA monitoring stations) in New England. Using the same data we performed AOD vs $\mathrm{PM}_{2.5}$ regression analysis by season (spring, summer, fall, and winter) for each of the three regions. In addition, we conducted AOD vs $\mathrm{PM}_{2.5}$ regression analysis by site location.

Next, we analyzed the intra-urban variability in AOD vs $\mathrm{PM}_{2.5}$ relationship inside a $10 \times 10 \mathrm{~km}^{2}$ area of greater Boston containing four EPA ground monitors and the Harvard Supersite. To take into account the variability of the sampling frequency of the EPA stations, only days with at least three available $A O D-\mathrm{PM}_{2.5}$ pairs inside a $10 \times 10 \mathrm{~km}^{2}$ box were selected (Figure 1, highlighted by the polygon). There were a total of 304 days with 3 5 observations. In addition, we analyzed $\mathrm{PM}_{2.5}$ vs $\mathrm{AOD}$ association in relation to $\mathrm{PM}_{2.5}$ particle levels, temperature, boundary layer height and relative humidity. Finally, we explored whether it is possible to obtain accurate estimates of $\mathrm{PM}_{2.5}$ concentrations using MAIAC $A O D$ retrievals and statistical modeling with a resolution of $1 \times 1 \mathrm{~km}^{2}$ conducted for Boston, MA in the northeastern part of U.S.

\subsection{Mixed effects model approach}

In this study we used a mixed-effects model approach that accounts for day-to-day variability. A basic assumption is that the relationship varies daily because it depends on time-varying parameters such as relative humidity, $\mathrm{PM}_{2.5}$ vertical and diurnal concentration profiles, $\mathrm{PM}_{2.5}$ optical properties and surface reflectance. In a recent paper, we showed that the mixed effects model approach provides higher accuracy and precision in predicting $\mathrm{PM}_{2.5}$ concentrations based on the MODIS AOD dataset than a simple regression model $[13,14]$. In the present study we use this model approach to predict $\mathrm{PM}_{2.5}$ concentrations based on MAIAC AOD retrievals. Consequently, quantitative relationships between $\mathrm{PM}_{2.5}$ concentrations measured at the $27 \mathrm{PM}_{2.5}$ monitoring sites and AOD values in their corresponding grid cells were derived. We used the following mixed effects model with random intercepts and slopes (Eq. 1):

$P M_{i j}=\left(\alpha+u_{j}\right)+\left[\left(\beta_{1}+v_{j}\right) \times A O D_{i j}\right]+S_{i}+\varepsilon_{i j}\left(u_{j} v_{j}\right) \sim\left[(o o), \Sigma_{\beta}\right]$

where $\mathrm{PM}_{i j}$ is the $\mathrm{PM}_{2.5}$ concentration at a spatial site $i$ on day $j ; A_{i j}$ is the AOD value in the grid cell cor- responding to site $\mathrm{i}$ on day $\mathrm{j} ; \alpha$ and $\mathrm{u}_{j}$ are the fixed and random intercepts, respectively; $\beta_{1}$ and $v_{j}$ are the fixed and random slopes, respectively; $\mathrm{Si} \sim \mathrm{N}(0, \sigma \mathrm{s} 2)$ is the random intercept of site $i$; $\varepsilon i j \sim N(0, \sigma 2)$ is the error term at site $\mathrm{i}$ on a day $\mathrm{j}$; and $\Sigma \beta$ is the variance-covariance matrix for the random effects. The AOD fixed effect in the model (Eq. 1) accounts for the effect of AOD on $\mathrm{PM}_{2.5}$, which was the same for all study days. The AOD random effects explain the daily variability in the $\mathrm{PM}_{2.5}$-AOD relationship. The solution of the mixed model equations is a maximum likelihood, a form of estimation that accounts for the parameters in the fixed-effects structure of the model to reduce the bias in the covariance parameter estimates [15]. Currently, this is the method implemented for the SAS statistical software package (proc mixed).

Finally, $\mathrm{PM}_{2.5}$ concentrations for each grid cell on a day j were estimated using the corresponding AOD values as follows:

$$
P M_{i j}=\left(\alpha+u_{j}\right)+\left[\left(\beta_{1}+v_{j}\right) \times A O D_{i j}\right]+\varepsilon_{i j}
$$

The fixed and random intercepts, and the fixed and random slopes for each study day were derived previously from Eq. 1. Note that the random estimates for the site term were excluded. In this way AOD values were unbiased and representative of their corresponding grid cell.

We use a cross-validation (CV) approach to evaluate the ability of the model to predict $\mathrm{PM}_{2.5}$ concentrations for each pixel in the study area. Thus, the dataset was repeatedly randomly divided into $90 \%$ (calibration) and $10 \%$ (held-out test) splits. We applied the fitted calibration model to estimate $\mathrm{PM}_{2.5}$ for the held-out test set. This "out-of-sample" process was repeated ten times to calculate the cross-validated (CV) $\mathrm{R}^{2}$ values.

\section{Results}

\subsection{Direct comparison with MOD04 retrieval}

This section studies the subset of MOD04/MAIAC data for days when both products are available for a given EPA site. Figure 2 shows the direct comparison between $\mathrm{PM}_{2.5}$ and AOD for MOD04 (10 km) and MAIAC (1 km) for the same days and locations (2002-2008) in New England (27 locations, $\mathrm{N}=2310, \mathrm{p}<0.0001)$. The coefficients of determination $\left(\mathrm{R}^{2}\right)$ for MOD04 and MAIAC are 0.45 and 0.50 respectively, suggesting that $A O D$ is a reasonably good proxy for $\mathrm{PM}_{2.5}$ ground concentrations. In other words, near-surface $\mathrm{PM}_{2.5}$ concentrations do not reflect the total AOD column values.

The previous research has shown that the $\mathrm{PM}_{2.5}$ vs $\mathrm{AOD}$ relationship varies seasonally and by location [16]. Ta- 
ble 2 presents a multi-year, seasonal (spring, summer, fall, winter) comparison between MOD04 and MAIAC. Although MAIAC shows intercepts that are lower than those for MOD04, for 8 year of measurements, slopes for both retrievals are similar, with the range of slopes between 7 $8 \mu \mathrm{g} / \mathrm{m}^{3}$ in winter and $26-31 \mu \mathrm{g} / \mathrm{m}^{3}$ in spring, summer and fall. The slight improvement in correlation is related to the finer resolution of MAIAC with its better correspondence between the monitoring site and the respective grid cell size, and better performance over bright urban areas.
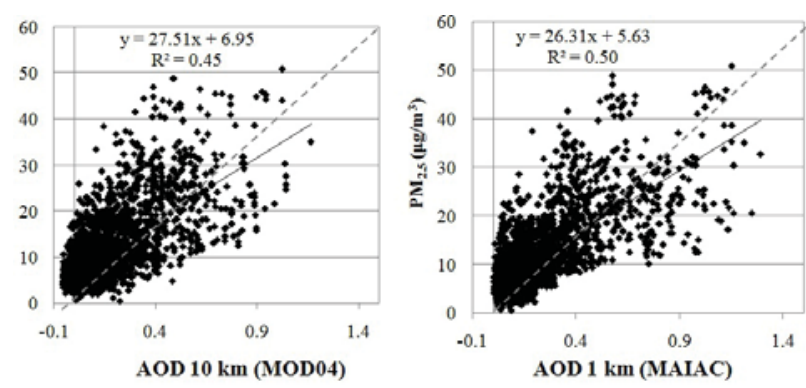

Figure 2. Comparison between $\mathrm{PM}_{2.5}$ and $\mathrm{AOD}$ for MODIS $10 \mathrm{~km}$ (MOD04) and MAIAC $1 \mathrm{~km}$ for the same days and locations (2002-2008) in New England (27 locations, $\mathrm{N}=2310$ ). The solid line represents the regression line, and the dashed line displays the $1: 1$ line.

Table 2. Seasonal comparison between coarse MOD04 AOD $10 \mathrm{~km}$ and fine resolution MAIAC $1 \mathrm{~km}$ AOD for the same days and locations.

\begin{tabular}{cccccc}
\hline Data Source & Statistics & Summer & Fall & Winter & Spring \\
\hline \hline \multirow{4}{*}{ MOD04 } & $N$ & 786 & 886 & 74 & 564 \\
& Intercept & 8.15 & 7.26 & 7.41 & 5.38 \\
& Slope & 26.3 & 28.9 & 7.7 & 26.2 \\
& $p$-value & $<.0001$ & $<.0001$ & 0.285 & $<.0001$ \\
& $R^{2}$ & 0.45 & 0.30 & 0.002 & 0.35 \\
\hline \multirow{4}{*}{ MAIAC } & $N$ & 786 & 886 & 74 & 564 \\
& Intercept & 6.08 & 5.8 & 7.04 & 3.56 \\
& Slope & 25.3 & 28.9 & 8.04 & 31.9 \\
& $p$-value & $<.0001$ & $<.0001$ & 0.226 & $<.0001$ \\
& $R^{2}$ & 0.50 & 0.35 & 0.007 & 0.41 \\
\hline
\end{tabular}

Figure 3 shows the frequency distribution of the correlation coefficient between $\mathrm{PM}_{2.5}$ and AOD by date for 20022008, for the same days and sites. In general, both retrievals provide a similar accuracy. Importantly, as can be also seen, the AOD vs $\mathrm{PM}_{2.5}$ relationship changes by date for both, MOD04 and MAIAC indicating a clear temporal variation in the association between both parameters. While Figure 3 shows the daily variability in AOD vs

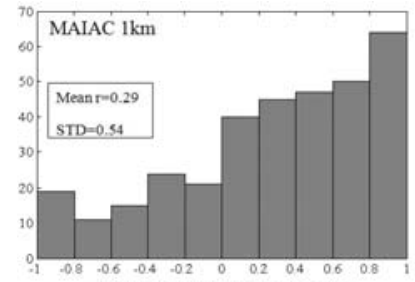

Correlation Coefficient by date

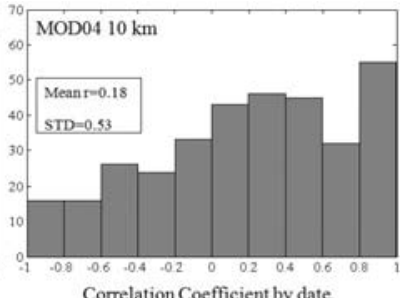

Correlation Coefficient by date
Figure 3. Frequency distribution of daily $\mathrm{AOD}$ vs $\mathrm{PM}_{2.5}$ correlations.

$\mathrm{PM}_{2.5}$ relationship, Figure 4 presents correlation coefficients between $\mathrm{PM}_{2.5}$ and AOD by the EPA site location for 2002-2008 (the same days were used for MAIAC and MOD04, $\mathrm{p}<0.005$ for all sites). In general, both retrievals provide similar results. Note that the range of correlations for both retrievals across the sites is substantial, which most likely reflects the local meteorological conditions and spatial homogeneity of $\mathrm{PM}_{2.5}$, namely how well the local $\mathrm{PM}_{2.5}$ measurement can be generalized to the larger footprint of the AOD pixel.

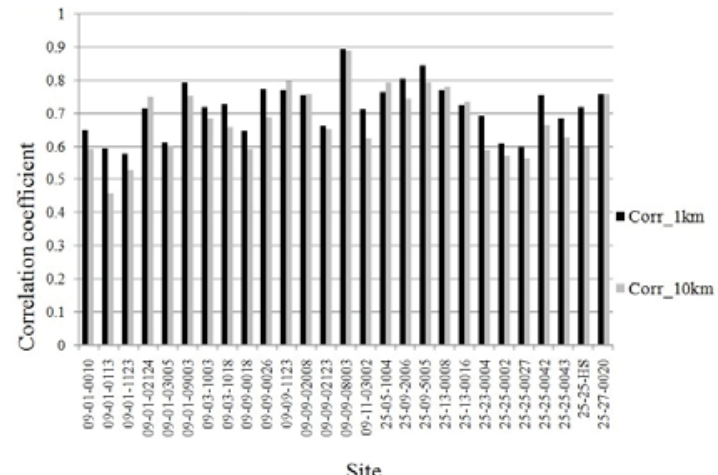

Figure 4. Correlation coefficient between $\mathrm{PM}_{2.5}$ and $\mathrm{AOD}$ by EPA site location for 2002-2008: dashed line indicates correlation for MAIAC and solid line for MOD04.

\subsection{Intra-urban variability in the $A O D$ vs $\mathrm{PM}_{2.5}$ relationship}

The high resolution AOD potentially carries information about local-scale variability, which is especially important for highly populated urban areas. We define the local variability as the variability in daily averaged $\mathrm{PM}_{2.5}$ values among different EPA stations (from 3 to 5 ) in the $10 \times 10 \mathrm{~km}^{2}$ box. Figure 5 shows an intra-urban AOD$\mathrm{PM}_{2.5}$ correlation in Boston with $\mathrm{R}^{2}=0.38$ for the entire study period 2002 - 2008 ( $N=304$ days). Each $\mathrm{PM}_{2.5}$ value for a given station in Figure 5 represents a daily averaged value. 


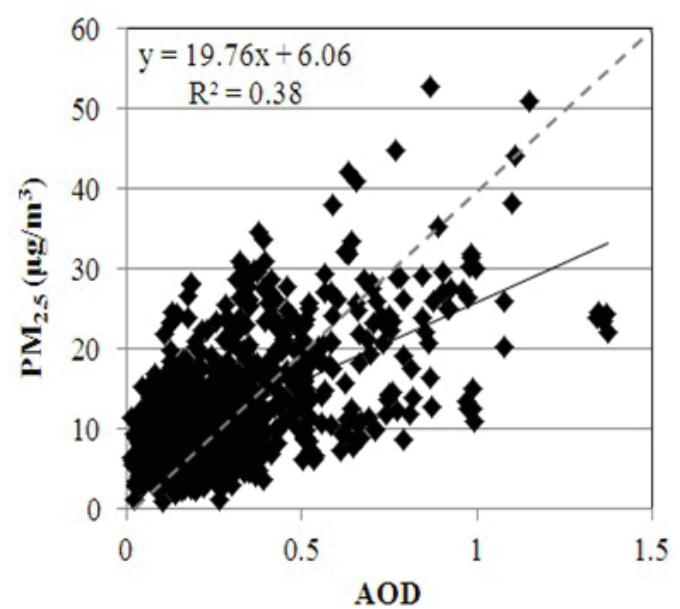

Figure 5. Intra-urban scatter plot between $\mathrm{PM}_{2.5}$ at EPA monitoring stations (with at least 3 ground $\mathrm{PM}_{2.5}$ measurements) and $1 \mathrm{~km}$ MAIAC AOD measured over the entire period 20022008 for Boston ( $\mathrm{N}=304$ days). The solid line represents the regression line, and the dashed line displays the 1:1 line.

First, we explored an intra-urban AOD-PM 2.5 correlation during different pollution days, based on EPA observations. Figure 6 shows correlation coefficient by date for different levels of daily averaged $\mathrm{PM}_{2.5}$ concentrations. As expected, at low $\mathrm{PM}_{2.5}$ levels $\left(<5 \mu \mathrm{g} / \mathrm{m}^{3}\right)$, the distribution of correlation coefficient is almost uniform in the range $[-1 ; 1]$ indicating low sensitivity of AOD and high relative errors of both $A O D$ and $\mathrm{PM}_{2.5}$. The correlation improves at higher $\mathrm{PM}_{2.5}$ levels, notably for ranges 5-10 and $10-20 \mu \mathrm{g} / \mathrm{m} 3$. The correlation seems to decrease at higher PM levels $(>20 \mu \mathrm{g} / \mathrm{m} 3)$ which may be an artifact of low sampling statistics.

The intra-urban AOD-PM 2.5 correlation (Figure 5) includes the temporal meteorological variability for 2002 2008. It has been shown that under conditions of a wellmixed boundary layer with low ambient relative humidity $(\mathrm{RH})$, the relationship between $\mathrm{PM}_{2.5}$ and $\mathrm{AOD}$ may be very robust [17]. With this in mind, in Figure 7a-c we studied the influence of temperature, relative humidity and boundary layer height $(\mathrm{BLH})$ on daily $\mathrm{PM}_{2.5}$ vs $\mathrm{AOD}$ correlations. Our results do not show any dependence of daily AOD-PM 2.5 correlations in the Boston metropolitan area on $\mathrm{RH}$ and air temperature below $7^{\circ} \mathrm{C}$. The correlation improves at higher temperatures, in particular above $7{ }^{\circ} \mathrm{C}$ typical of late spring-summer-early fall conditions. Figure $7 \mathrm{~b}$ also shows an improved correlation for the moderate boundary layer heights of $250-500 \mathrm{~m}$, and a poorer correlation outside of this range. Some of these results have a clear physical explanation: for example, the low

\section{Daily averaged concentrations of $\mathrm{PM}_{2.5}$}
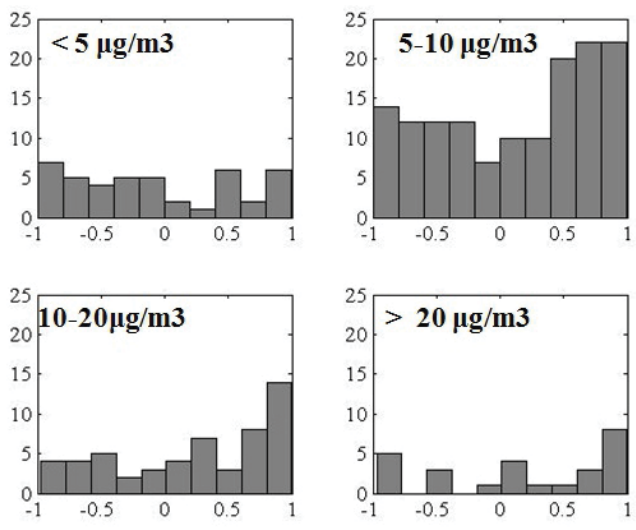

Figure 6. Correlation coefficient as a function of spatial variability in $\mathrm{PM}_{2.5}$ concentrations.

temperatures with shallow BLH are associated with winter conditions when average $\mathrm{PM}_{2.5}$ and $\mathrm{AOD}$ are low and one cannot expect good AOD-PM 2.5 correlation.

\subsection{Prediction of $\mathrm{PM}_{2.5}$ concentrations using mixed effect model approach}

Since these relationships between AOD and $\mathrm{PM}_{2.5}$ measurements vary daily, mixed effects models were used to allow for the regression intercepts and slopes to vary daily. The fixed effects of the AOD intercept and slope were statistically significant: $\alpha=9.3(\mathrm{p}<0.0001)$ and $\beta_{1}=17.2(\mathrm{p}<0.0001)$ respectively. The fixed effects of spatial and temporal predictors were also significant. In addition, the random slopes for AOD by day, and by day and region were both significant $(p<0.0001)$. Figure 8 shows the daily variation of random AOD intercepts and slopes. Note that these results support the findings that because the parameters influencing the relationship between $\mathrm{PM}_{2.5}$ and AOD vary from day to day within a given domain, it is necessary to adjust for this daily variability.

The measured and predicted $\mathrm{PM}_{2.5}$ concentrations in the cross validation (CV) model are shown in Figure 9. As can be seen, the $C V$ mixed effects model performed quite well. The CV test resulted in a $R^{2}$ value of 0.90 and slope of 0.91, indicating a good agreement between the measured and predicted concentrations.

Finally, the model was applied for retrieval days to explore the pattern of $\mathrm{PM}_{2.5}$ concentrations on a daily basis. June 25th was selected as the high pollution event to analyze the predicted $\mathrm{PM}_{2.5}$ concentrations resulting from the mixed effect model approach. During this day, the average concentrations on EPA monitoring stations in the 


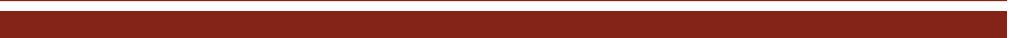

\section{Temperature}
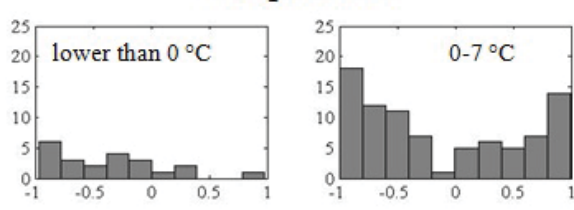

\section{Boundary layer height $(\mathrm{m})$}
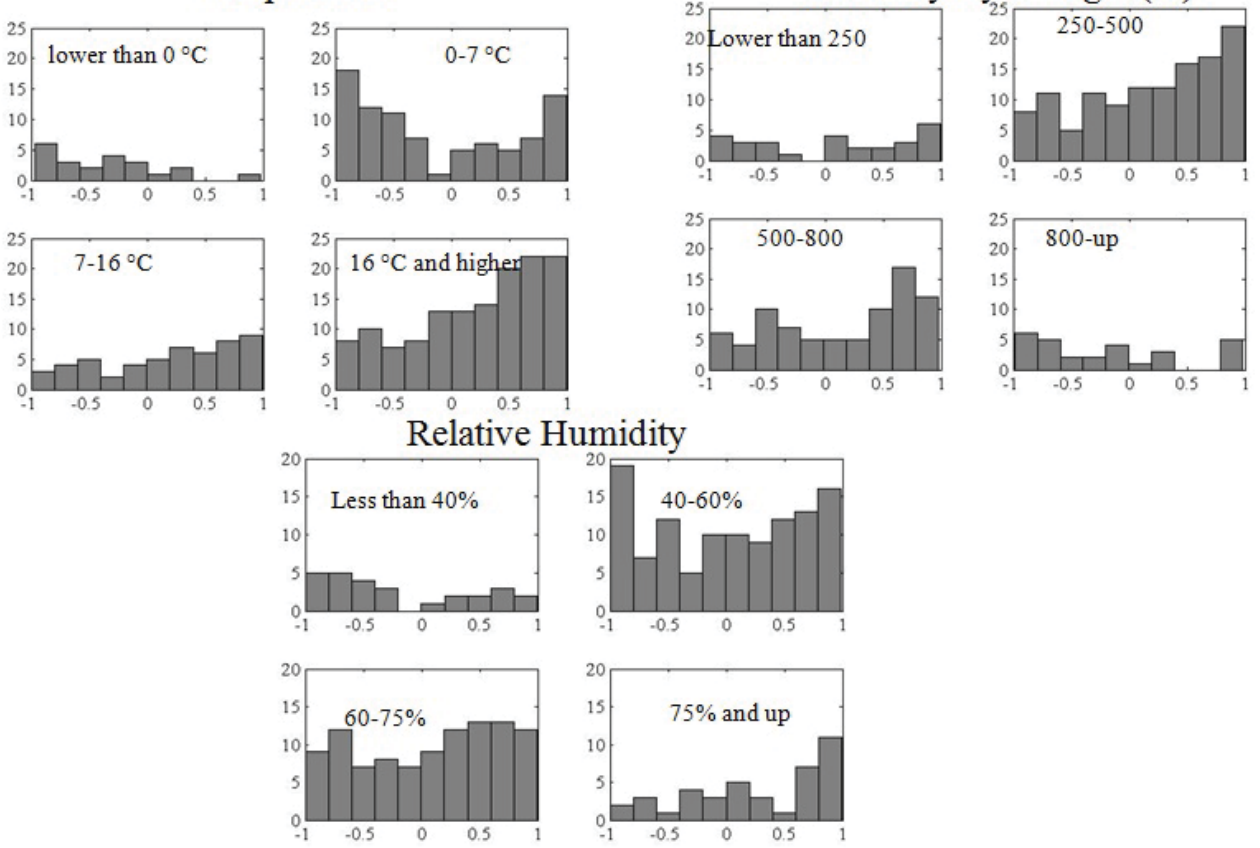

Figure 7. Correlation coefficient by date conditioned at several meteorological parameters: a) temperature, b) boundary layer height, and c) relative humidity.
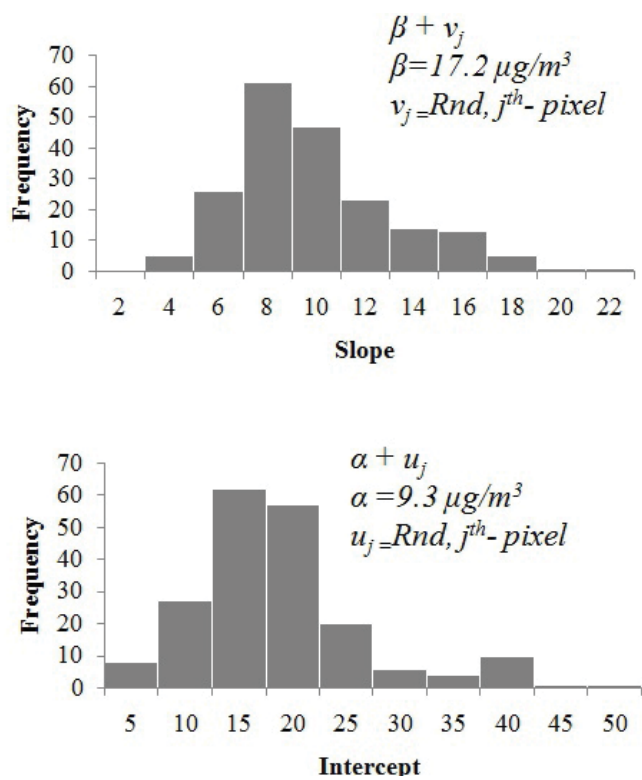

Figure 8. Frequency distribution of the random intercepts and slopes.

New England area ranged between 25-42 $\mu \mathrm{g} / \mathrm{m} 3$. During 20-24th of June 2003, a forest fire in the Quebec province, Canada, brought smoke pollution into Massachusetts, NE. Figure 10 presents a MODIS Level 1B true-color image
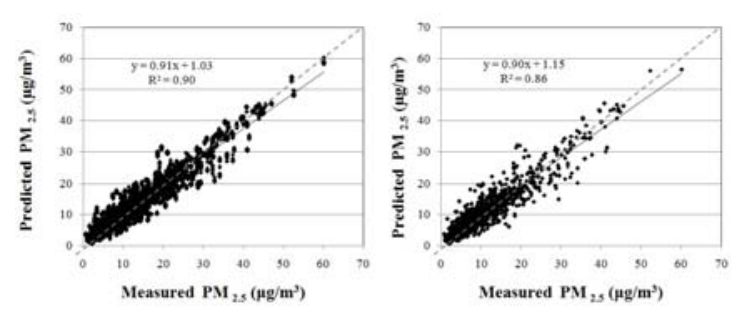

Figure 9. Measured vs predicted $\mathrm{PM}_{2.5}$ concentrations for the crossvalidation model (left) and the test set (right). The solid line represents the regression line, and the dashed line displays the 1:1 line.

and shows long range transport of thick haze from fires in the Quebec province, Canada on June 24, 2003 (A) and June 25, 2003 (B) (left, red arrow) along the eastern seaboard of the U.S. Figure $9 \mathrm{C}$ and $\mathrm{D}$ highlight high AOD values at $550 \mathrm{~nm}$ (right) which are elongated with the plum.

In Figure 11 we show the spatial pattern of $\mathrm{PM}_{2.5}$ concentrations resulting from the mixed effect model on June 25,2003 . As can be seen, the spatial concentration patterns are different across the domain and are highest in Boston due to high pollution transport from forest fires in Canada. Importantly, as shown in Figure 11, the variability in $\mathrm{PM}_{2.5}$ concentrations at fine scale resolution can be high even during high pollution events when the contrast 


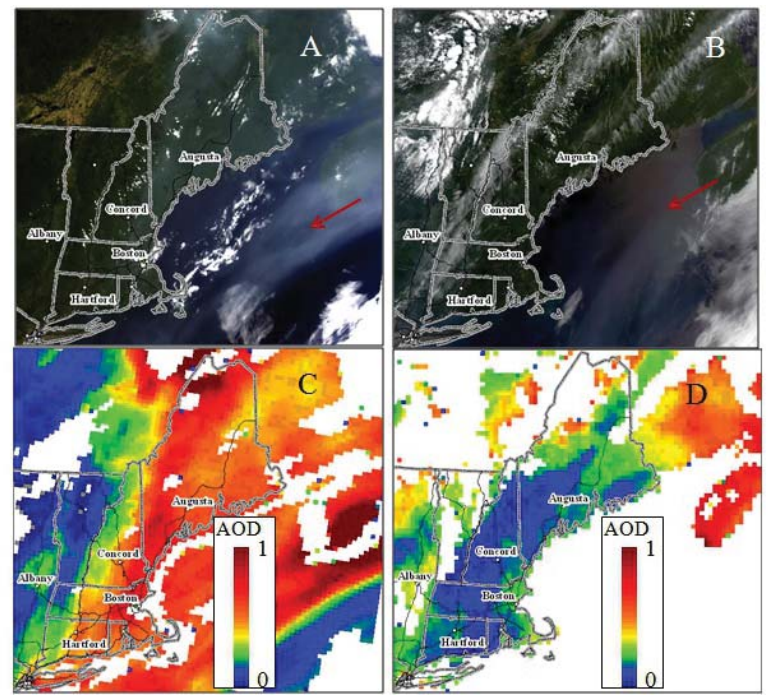

Figure 10. Maps A and B: MODIS Level 1B true-color image shows long range transport of thick haze from fires in the Quebec province, Canada on June 24, 2003 (A) and June 25, 2003 (B) (left, red arrow) along the eastern seaboard of the U.S. Maps C and D: High AOD values at $550 \mathrm{~nm}$ (right) are elongated with the plume.

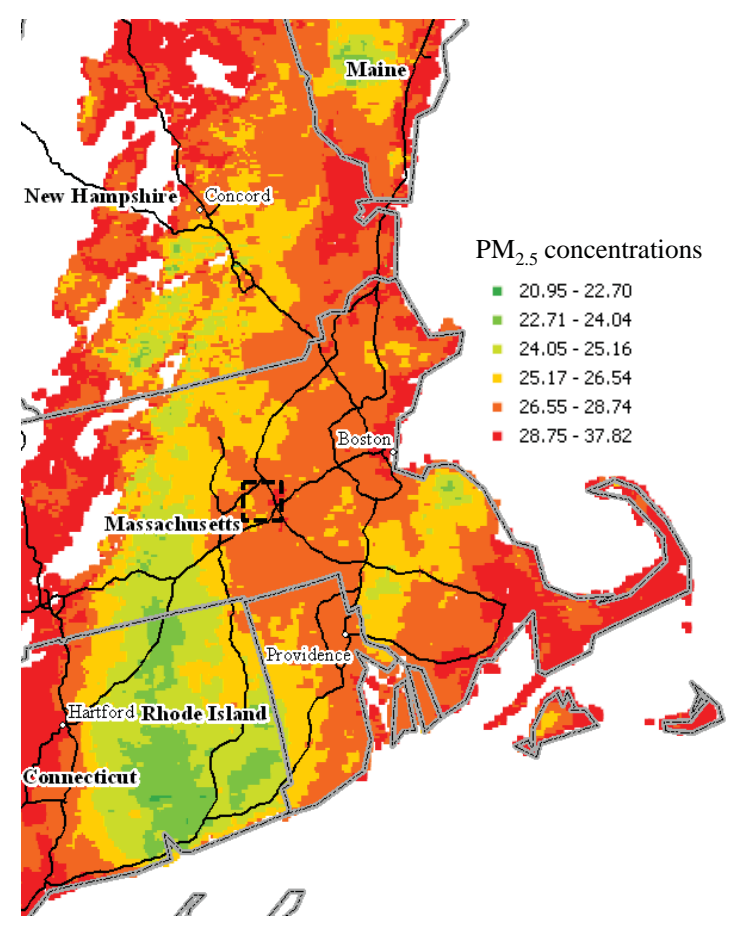

Figure 11. $\mathrm{PM}_{2.5}$ concentrations modeled by mixed effects approach for June 25, 2003. in pollution levels between geographically adjacent areas is not expected to be high. Compare dashed line 1 on Figure 11: for the area of $\sim 20 \mathrm{~km}$, variability in particle concentration $\sim 4 \mu \mathrm{g} / \mathrm{m}^{3}$ that can be captured by the model. Furthermore, the fine resolution results indicated spatial variability at a sub-10 kilometer scale.

\section{Conclusions}

This paper analyzed how the spatial resolution of the AOD product affected the correlation between satelliteretrieved $A O D$ and ground based $\mathrm{PM}_{2.5}$ concentrations using 7 years of MODIS Terra observations over the southern part of New England. A direct comparison between coarse MOD04 $10 \mathrm{~km} \mathrm{AOD}$ and high resolution MAIAC $1 \mathrm{~km}$ AOD for all collocated AOD-PM 2.5 pairs for the same days and locations showed that although both retrievals provide reasonable results, MAIAC was found to provide a slightly better correlation. Furthermore, there is clear temporal variation in the association between AOD and $\mathrm{PM}_{2.5}$. Importantly, a local analysis for Boston area showed that AOD-PM 2.5 relationship does not depend on $\mathrm{RH}$ and air temperatures below $\sim 7^{\circ} \mathrm{C}$. The correlation improves for temperatures above $7-16^{\circ} \mathrm{C}$. We found a poorer correlation between $\mathrm{AOD}$ and $\mathrm{PM}_{2.5}$ on days with very low or very high boundary layer height.

From the epidemiological and exposure assessment point of view, it is of high importance to have information about the spatial variability of the exposures in the city. Several studies published in the last 3 years have shown that high spatial resolution is essential to detect spatial variability in PM levels [18] and in aerosol loadings at regional and at a sub-10 km scale (e.g. intra-urban domain) $[19,20]$. Our study using MAIAC data and mixed effect approach showed high accuracy in the New England domain thereby indicating that our model based on MAIAC data can be used to investigate the intra-urban exposure contrasts in $\mathrm{PM}_{2.5}$ levels.

Our results show a daily adjustment using a mixed effects model approach effectively controls the combined effects of many parameters that can influence the daily variability in the AOD- $\mathrm{PM}_{2.5}$ relationship. This implies that within a given region, the types of aerosols may be more homogeneous and the height of the boundary layer and humidity may be more uniform, making the relationship between AOD to $\mathrm{PM}_{2.5}$ less variable. Therefore, the proposed method has the advantage that it can easily be applied to other regions by taking into account the conditions prevailing in each region, and adjusting for daily variability in the AOD vs $\mathrm{PM}_{2.5}$ relationship.

Despite promising results, more data need to be processed 
and analyzed to understand the full potential and limitations of the high resolution MAIAC AOD product for improving the accuracy in $\mathrm{PM}_{2.5}$ estimations. Next, additional parameters can be considered in the model thereby improving the accuracy of $\mathrm{PM}_{2.5}$ estimates. Furthermore, in order to further investigate the strengths and limitations of using high resolution satellite AOD data for the routine modeling of $\mathrm{PM}_{2.5}$ concentrations during high and low pollution days we are planning to conduct a comprehensive multi-year study based on the full set of MODIS measurements. Next, further improvements to the MAIAC AOD retrieval algorithm would improve accuracy in $\mathrm{PM}_{2.5}$ estimation. It is important to emphasize though, that the information content of AOD data alone is limited, and the best results may be achieved by combining different data sources including, for example, the aerosol vertical profile information from satellite or ground-based lidars.

\section{Acknowledgments}

This work was made possible by USEPA grant RD 83479801. Its contents are solely the responsibility of the grantee and do not necessarily represent the official views of the USEPA. Further, USEPA does not endorse the purchase of any commercial products or services mentioned in the publication. Authors greatly appreciate inspiring discussions with Prof. Alex Kostinski from Michigan Technological University, USA. Authors greatly appreciate important comments of Dr. Mike Wolfson.

\section{References}

[1] Monks P., A. Baklanov, Simpson D., Fuzzi S., Stohl A., Williams M.L., Akimoto H., M. Amann et al., Atmospheric composition change - global and regional air quality, Atmos. Environ. 2009, 43, 5268-5350

[2] Miller K., Siscovick D., Sheppard L., Shepherd K., Sullivan J., Anderson G., Kaufman J., Long-term exposure to air pollution and incidence of cardiovascular events in women. New England Journal of Medicine 356, 447-458. (2007).

[3] Lepeule J., Laden F, Dockery D, Schwartz J.Chronic exposure to fine particles and mortality: an extended follow-up of the Harvard six cities study from 1974 to 2009. Environmental Health Perspectives 2012, 120, 965-970

[4] Pope III C.A., Burnett R.T., Thun M.J., Calle E.E., Krewski D., Ito K., Thurston G.D., Lung cancer, cardiopulmonary mortality, and long-term exposure to fine particulate pollution. JAMA: the Journal of the
American Medical Association, 2002, 287, 1132-41

[5] Zhu Y, Skuhn, Mayo P, Hinds W., Comparison of Daytime and Nighttime Concentration Profiles and Size Distributions of Ultrafine Particles near a Major Highway. Environmental Science and Technology, 2006, 40, 2531-2536

[6] Bell M., Ebisu K., Peng R., Community-level spatial heterogeneity of chemical constituent levels of fine particulates and implications for epidemiological research. J. Exposure Science and Environ. Epidemiol., 2010, 24, 1-13, doi:10.1038/jes.2010.24

[7] Hoff R., Christopher S., Remote Sensing of Particulate Pollution from Space: Have We Reached the Promised Land? J. Air Waste Manage Assoc., 2009, 59, 645-675

[8] Lyapustin A., Wang Y., Laszlo I., Kahn R., Korkin S., Remer L., Levy R., Reid J.S., Multi-Angle Implementation of Atmospheric Correction (MAIAC): Part 2. Aerosol Algorithm, J. Geophys. Res., 2011, 116, D03211, doi:10.1029/2010JD014986

[9] Levy R.C., Remer L.A., Mattoo S., Vermote E.F., Kaufman Y.J., Second-generation operational algorithm: Retrieval of aerosol properties over land from inversion of Moderate Resolution Imaging Spectroradiometer spectral reflectance. J. Geophys. Res., 2007, 112, D13

[10] Holben B.N., Coauthors, 1998: AERONET-A federated instrument network and data archive for aerosol characterization. Remote Sens. Environ.,1998, 66, 116

[11] Lyapustin A, Wang Y, Frey R. An Automatic Cloud Mask Algorithm Based on Time Series of MODIS Measurements. J. Geophys. Res., 2008, 113, D16207, doi:10.1029/2007JD009641

[12] Remer L.A., Kaufman Y.J., Tanre D., Mattoo S., Chu D.A., Martins J.V., Li R.R., Ichoku C., Levy R.C., Kleidman R.G., Eck T.F., Vermote E., Holben B.N.: The MODIS aerosol algorithm, products, and validation, J. Atmos. Sci., 2005, 62, 947-973

[13] Lee H.J., Liu Y., Coull B.A., Schwartz J., Koutrakis P., A novel calibration approach of MODIS AOD data to predict $\mathrm{PM}_{2.5}$ concentrations. Atmos. Chem. Phys., 2011, 11, 7991-8002

[14] Chudnovsky A., Hyung J.L., Kostinski A., Kotlov T., Koutrakis P., Prediction of daily fine particulate matter concentrations using aerosol optical depth retrievals from the Geostationary Operational Environmental Satellite. Journal of the Air \& Waste Management Association, 2012, 62, 1022-1031, DOI: 10.1080/10962247.2012.695321

[15] Lindstrom M.L., Bates D.M., Newton-Raphson and EM algorithms for linear mixed-effects models for 
repeated-measures data. JASA Journal of the Acoustical Society of America 1998, 83, 1014-1021

[16] Zhang H., Hoff R.M., Engel-Cox J.A., The Relation between MODIS Aerosol Optical Depth and $\mathrm{PM}_{2.5}$ over the United States: a Geographical Comparison by EPA Regions. J. Air \& Waste Manage. Assoc., 2009, 59, 1358-1369

[17] Gupta P., Christopher S.A., Particulate matter air quality assessment using integrated surface, satellite, and meteorological products: 2. A neural network approach. J. Geophys. Res., 2009, 114, D20205, doi:10.1029/2008JD011497

[18] Kumar N., Foster A., Chu A., Peters T., Willis R.,
Satellite Remote Sensing for Developing Time-Space Resolved Estimates of Ambient Particulate in Cleveland, OH. Aeros. Sci. Technol., 2011, 45, 1090-1108, DOI: $10.1080 / 02786826.2011 .581256$

[19] Chudnovsky A., Kostinski A., Lyapustin A., Koutrakis P., Spatial scales of pollution from variable resolution satellite imaging. Environ. Pollut., 2013, 172, 131138

[20] Emili E., Lyapustin A., WangY., Popp C., Korkin S., Zebisch M., High spatial resolution aerosol retrieval with MAIAC: Application to mountain regions. J. Geophys. Res., 2011, 116, D23211 